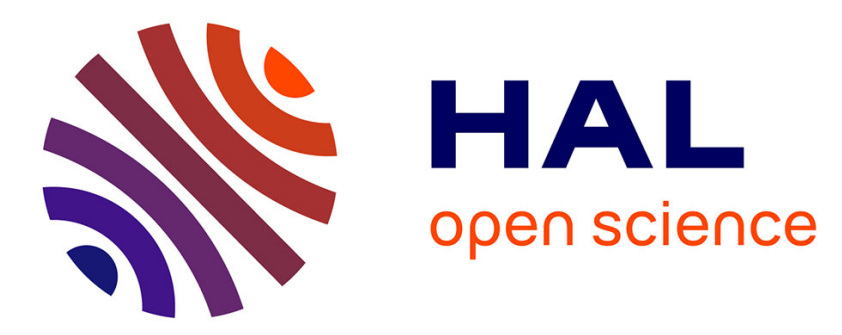

\title{
Synthesis of Triazole-Functionalized Diblock Copolymers as Templates for Porous Materials
}

Melisa Trejo-Maldonado, Luis Ernesto Elizalde, Benjamin Le Droumaguet, D.

Grande

\section{- To cite this version:}

Melisa Trejo-Maldonado, Luis Ernesto Elizalde, Benjamin Le Droumaguet, D. Grande. Synthesis of Triazole-Functionalized Diblock Copolymers as Templates for Porous Materials. Reactive and Functional Polymers, 2021, 164, pp.104919. 10.1016/j.reactfunctpolym.2021.104919 . hal-03214749

\author{
HAL Id: hal-03214749 \\ https://hal.science/hal-03214749
}

Submitted on 2 May 2021

HAL is a multi-disciplinary open access archive for the deposit and dissemination of scientific research documents, whether they are published or not. The documents may come from teaching and research institutions in France or abroad, or from public or private research centers.
L'archive ouverte pluridisciplinaire HAL, est destinée au dépôt et à la diffusion de documents scientifiques de niveau recherche, publiés ou non, émanant des établissements d'enseignement et de recherche français ou étrangers, des laboratoires publics ou privés. 


\section{Synthesis of Triazole-Functionalized Diblock Copolymers as Templates for 2 Porous Materials}

3

\author{
${ }^{1}$ Centro de Investigación en Química Aplicada, Blvd. Enrique Reyna Hermosillo, 140, 25100 Saltillo, \\ Coahuila, México \\ ${ }^{2}$ Univ Paris Est Creteil, CNRS, Institut de Chimie et des Matériaux Paris-Est (ICMPE), UMR 7182, 2 \\ rue Henri Dunant, 94320 Thiais, France \\ Corresponding authors: luis.elizalde@ciqa.edu.mx (L.E. Elizalde); grande@icmpe.cnrs.fr (D. Grande)
}

\section{Abstract}

A versatile approach toward porous polystyrene-based frameworks functionalized with triazolyl moieties is reported. These porous materials were prepared from poly(D,L-lactic acid)-blockpoly(styrene-stat-4-azidomethylstyrene) (PLA-b-P(S-stat-4-AMS)) diblock copolymer precursors. Upon macroscopic orientation and subsequent alkaline hydrolysis of the PLA block, such triazolylcontaining porous polystyrenes were produced. Experimentally, a PLA macroinitiator was synthesized by ring-opening polymerization (ROP) of D,L-lactide using a heterobifunctional initiator. The prepared macroinitiator containing a terminal tertiary $\alpha$-bromo ester group allowed for further ATRP statistical copolymerization of styrene and 4-azidomethylstyrene, affording the second block, i.e. the $\mathrm{P}(\mathrm{S}$-stat-4-AMS) block. The styrene to 4-azidomethylstyrene molar ratio was tuned to obtain various compositions of the hydrophobic block. PLA macroinitiators and corresponding PLA- $b$-P(Sstat-4-AMS) diblock copolymers were fully characterized by size exclusion chromatography (SEC), ${ }^{1} \mathrm{H}$ and ${ }^{13} \mathrm{C}$ NMR, Fourier Transform Infrared (FT-IR) spectroscopy, and differential scanning calorimetry (DSC). Functionalization of PLA-b-P(S-stat-4-AMS) diblock copolymers with $p$ tolylacetylene or 2-methyl-3-butyn-2-ol was carried out via copper-catalyzed azide-alkyne cycloaddition (CUAAC), yielding triazole ring in high yields (>90\%). Finally, the porous structure of such functional polystyrene frameworks was examined by SEM.

Keywords: diblock copolymers; CuAAC "click" reaction; triazole; porous materials 


\section{Introduction}

2

Over the last decade, functionalized porous materials have gained increasing interest from the research community in different areas, such as microelectronics, [1] energy storage, [2] photonics, [3] separation, [4-5] environmental remediation, [6] and biotechnology, [7] among others. The real breakthrough in these applications deals not only with their peculiar morphology but also with the specific properties they may offer, such as interaction between the porous material and the target molecules through a fast mass transfer, high specific surface area, and when hierarchically structured, they develop the capability of mimicking natural structures. [8-9] Actually, the porous materials by themselves cannot improve any useful property in the above-mentioned applications and require, in most cases, the introduction of chemical groups inserted in the backbone that can interact with metal ions, especially in the preparation of metal-organic frameworks (MOFs) [10] or mesoporous metal-based materials (MMBMs). [11]

To date, porous polymeric materials can be prepared through several self-assembling procedures according to a bottom-up strategy; this technique notably relies on functional block copolymers, constituted of an inert block and a labile (sacrificial) one, [12-13] which undergo self-assembly followed by the elimination of the labile block. Polystyrene-block-poly(D,L-lactic acid) (PS- $b$-PLA) semi-degradable diblock copolymers have been widely used in the two last decades for the preparation of such nanoporous polymers. The porosity has been created either by selective degradation of the PLA block or alternatively by a smarter strategy implying the selective cleavage of a chemical junction present between alien blocks. [14-27] The latter has notably allowed for the facile release of chemical functionalities of interest that can be further implemented for pore surface functionalization. When porous metal-based materials are demanded, the addition of metal ions are common; however, the only expected interactions between the copolymer backbone and the metal ion are through Van der Waals forces. In this regard, few publications emphasize improving the strength of these interactions by functionalizing a stable block copolymer with chemical groups of interest that can reach stronger interactions with the metal ions by coordinate covalent bonds. [28-31]

The use of amphiphilic block copolymers followed by an induced or cooperative self-assembly has noteworthy advantages; the extent of the interactions between antagonist blocks could be predicted, based on the chemical nature of each block and their intrinsic physicochemical properties 
1 such as molar mass, molar mass distribution, block composition and solubility. [32] Amphiphilic

2 block copolymers with tunable molar masses, narrow molar mass distributions, and high end-

3 functionality can be obtained by controlled radical polymerization (CRP) techniques. Particularly,

4 reactive/functional end-groups can promote post-polymerization reactions to obtain functionalized

5 macromolecules. [15, 24, 28] Atom Transfer Radical Polymerization (ATRP) is one of the most

6 employed CRP processes due to its viability to polymerize a wide spectrum of functional monomers

7 in a controlled manner, particularly for post-polymerization reactions, such as block extension or

8 end group functionalization. Besides, adding one or more blocks with dissimilar chemistry is possible

9 towards the preparation of biphasic systems when ATRP is combined with other polymerization

10 techniques. These chemical features inherent to each block enable their phase segregation,

11 promoting self-assembly of the domains at a nano/mesoscale, resulting in a hierarchically ordered

12 structure.

13 Herein, we report on the synthesis of functionalized poly(D,L-lactide)-block-poly(styrene-statistical-

14 4-azidomethylstyrene) (PLA-b-P(S-stat-4-AMS) diblock copolymers and their further

15 functionalization to afford the corresponding diblock copolymers exhibiting various quantities of 16 triazolyl moieties which could be used in the preparation of porous functional polymeric materials.

17 The as-obtained amphiphilic block copolymer is constituted of a stable block containing a tuned

18 quantity of triazolyl groups embedded in the polymer chain and of a degradable PLA block that is

19 notably sensitive to alkaline conditions. In the functionalized polystyrene block, the triazolyl groups

20 are incorporated through the concomitant polymerization of styrene and 4-azidomethylstyrene (4-

21 AMS), used as co-monomer, followed by the copper-catalyzed azide-alkyne cycloaddition (CuAAC)

22 of two different acetylenic compounds. Further, some features of the porous morphology arising

23 from such triazolyl functionalized diblock copolymers are given.

\section{Experimental Section}

\subsection{Materials}

27 The solvents were dried, as already reported in the literature. [33] Copper (I) bromide and copper 28 (I) chloride (Aldrich, 99\%) were purified by stirring in glacial acetic acid, then with several successive 29 washings with methanol, and finally with anhydrous diethyl ether before drying overnight under 30 vacuum. Dimethylaminopyridine (DMAP, >99\%), 2-bromoisobutyryl bromide (>98\%), $N, N, N^{\prime}, N^{\prime \prime}, N^{\prime \prime}-$ 
pentamethyldiethylenetriamine (PMDETA, 99\%), 4-chloromethyl styrene (97\%), triethylamine (TEA, 99.5\%), ethylene glycol (99.8\%, anhydrous), and sodium azide ( $\left.\mathrm{NaN}_{3}, \geq 99.5 \%\right)$ were obtained from Aldrich and used as received. Styrene (Aldrich, 99\%) was washed with $\mathrm{NaOH}$ and distilled from $\mathrm{LiAlH}_{4}$ under vacuum prior to use. D,L-Lactide (Aldrich, 99\%) was lyophilized from toluene overnight prior to use. Other reagents and solvents were used without any further purification procedures unless otherwise stated.

\subsection{Synthesis of 2-hydroxyethyl 2-bromoisobutyrate (HEBI) (1)}

The synthesis of HEBI is adapted from an already reported procedure. [34] It is as follows: Ethylene glycol $(5.54 \mathrm{~g}, 89.4 \mathrm{mmol})$ and TEA $(6.78 \mathrm{~g}, 67.0 \mathrm{mmol})$ were placed into a $250 \mathrm{~mL}$ round-bottom flask and diluted with $50 \mathrm{~mL}$ of dichloromethane. 2-bromoisobutyryl bromide (5.14 g, $89.0 \mathrm{mmol})$ was added dropwise into the mixture in a time-lapse of $2 \mathrm{~h}$ at $0{ }^{\circ} \mathrm{C}$. Upon completion of the addition, the reaction mixture was warmed to room temperature, and a catalytic amount of DMAP was added to the reaction. Finally, the reaction mixture was refluxed for 3 additional $h$. The obtained product was purified via vacuum distillation, isolating a colorless viscous liquid (10.19 g, $45 \%$ yield). ${ }^{1} \mathrm{H}$ NMR $\left(\mathrm{CDCl}_{3}\right.$ at $\left.25^{\circ} \mathrm{C}, 500 \mathrm{MHz}\right): \delta(\mathrm{ppm}): 4.2\left(\mathrm{t}, 2 \mathrm{H}, J=4.30 \mathrm{~Hz}, \mathrm{C}(=\mathrm{O}) \mathrm{O}-\mathrm{C}_{2}\right) ; 3.8\left(\mathrm{t}, 2 \mathrm{H}, J=4.5 \mathrm{~Hz}, \underline{\mathrm{C}}_{2}-\right.$ $\mathrm{OH}) ; 1.9\left(\mathrm{~s}, 6 \mathrm{H},-\underline{\mathrm{CH}}_{3}\right) .{ }^{13} \mathrm{C} \mathrm{NMR}\left(\mathrm{CDCl}_{3}\right.$ at $\left.25{ }^{\circ} \mathrm{C}, 125 \mathrm{MHz}\right): 171.3(\underline{\mathrm{C}}=\mathrm{O}), 64.1\left(-\underline{\mathrm{CH}}_{2^{-}}\right), 60.7\left(-\mathrm{OCH}_{3}\right)$,

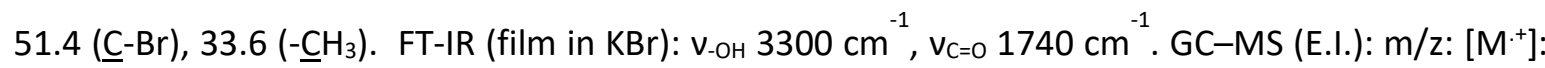
$210(30), 212(30)$

\subsection{Synthesis of 4-azidomethylstyrene (4-AMS) (3)}

4-chloromethylstyrene $(10.0 \mathrm{~g}, 65 \mathrm{mmol})$ and sodium azide $(8.45 \mathrm{~g}, 130 \mathrm{mmol})$ were mixed with 70 $\mathrm{mL}$ acetone in a $100 \mathrm{~mL}$ round-bottom flask. The mixture was refluxed for about $90 \mathrm{~h}$. The organic phase was diluted with $\mathrm{CHCl}_{3}$, washed with $\mathrm{H}_{2} \mathrm{O}$, dried over $\mathrm{MgSO}_{4}$, and vacuum-dried to afford the desired product as an orange viscous liquid (10.21 g, 98\% yield). ${ }^{1} \mathrm{H}$ NMR $\left(\mathrm{CDCl}_{3}\right.$ at $\left.25^{\circ} \mathrm{C}, 500 \mathrm{MHz}\right)$ : $\delta(p p m): 7.38\left(\mathrm{~d}, 2 \mathrm{H}, \mathrm{H}_{\mathrm{A}}, \mathrm{J}_{\mathrm{HA}-\mathrm{HB}}=8.09 \mathrm{~Hz}\right) ; 7.23\left(\mathrm{~d}, 2 \mathrm{H}, \mathrm{H}_{\mathrm{B}}, \mathrm{J}_{\mathrm{HB}-\mathrm{HA}}=8.23 \mathrm{~Hz}\right) ; 6.68\left(\mathrm{dd}, 1 \mathrm{H}, \mathrm{H}_{3}, \mathrm{~J}_{\mathrm{H} 3-\mathrm{H} 1}=\right.$ $\left.10.97 \mathrm{~Hz}, \mathrm{~J}_{\mathrm{H} 3-\mathrm{H} 2}=17.63 \mathrm{~Hz}\right) ; 5.73\left(\mathrm{dd}, 1 \mathrm{H}, \mathrm{H}_{2}, \mathrm{~J}_{\mathrm{H} 2-\mathrm{H} 1}=0.84 \mathrm{~Hz}, \mathrm{~J}_{\mathrm{H} 2-\mathrm{H} 3}=17.57 \mathrm{~Hz}\right) ; 5.24\left(\mathrm{dd}, 1 \mathrm{H}, \mathrm{H}_{1}, \mathrm{~J}_{\mathrm{H} 1-}\right.$ $\left.\mathrm{H}_{2}=0.64 \mathrm{~Hz}, \mathrm{~J}_{\mathrm{H} 1-\mathrm{H} 3}=10.75 \mathrm{~Hz}\right) ; 4.26\left(\mathrm{~s}, 2 \mathrm{H},-\mathrm{CH}_{2}-\mathrm{N}_{3}\right) \cdot{ }^{13} \mathrm{C} \mathrm{NMR}\left(\mathrm{CDCl}_{3}\right.$ at $\left.25{ }^{\circ} \mathrm{C}, 125 \mathrm{MHz}\right): \delta(\mathrm{ppm})$ : 137.7 (Aromatic Carbon), $136.2\left(-\underline{\mathrm{CH}}=\mathrm{CH}_{2}\right), 134.8$ (Aromatic Carbon), 128.4 (Aromatic Carbon), 126.6 (Aromatic Carbon), $114.4\left(-\mathrm{CH}=\underline{\mathrm{CH}}_{2}\right), 54.6\left(-\underline{\mathrm{CH}}_{2}-\mathrm{N}_{3}\right)$. FT-IR (film in KBr): $\mathrm{v}_{\mathrm{C}=\mathrm{C}-\mathrm{H}} 3000 \mathrm{~cm}^{-1}, \mathrm{v}_{-\mathrm{N} 3} 2097.60$ cm $^{-1}$. GC-MS (E.I.): m/z: [M+']: 159 (30), 116.9 (100). 
2.4. General procedure for the synthesis of poly(D,L-lactic acid) PLA macroinitiator (2)

2-hydroxyethyl-2-bromo-2-methyl propanoate (HEBI, $0.39 \mathrm{~g}, 1.87 \mathrm{mmol}$ ) and tin (II) 2-

4 ethylhexanoate $(1.53 \mathrm{~g}, 3.75 \mathrm{mmol})$ were mixed with $40 \mathrm{~mL}$ dry toluene in a $100 \mathrm{~mL}$ Schlenk tube.

5 The solution was degassed with 3 freeze-pump-thaw cycles. Inside a glove box, 1,4-dioxane-2,5dione ( $\mathrm{D}, \mathrm{L}$-lactide) $(5.0 \mathrm{~g}, 69.3 \mathrm{mmol})$ was added into a $30 \mathrm{~mL}$ quartz tube containing one-third of the solution previously prepared. This process was repeated twice in two more tubes. Each tube was place independently in a microwave reactor at $110{ }^{\circ} \mathrm{C}$ for $5 \mathrm{~h}$ and $30 \mathrm{~min}$. The device was programmed to reach such a temperature after $5 \mathrm{~min}$ from room temperature. At the end of the reaction, toluene was evaporated, the residue was dissolved in dichloromethane and precipitated in a mixture $1 / 1$ hexane/diethyl ether: $1 / 1(\mathrm{v} / \mathrm{v})$. The obtained solid $(4.65 \mathrm{~g}, 93 \%$ yield) was dried under vacuum for at least $12 \mathrm{~h}$ in each case and was further analyzed by ${ }^{1} \mathrm{H} N \mathrm{NM},{ }^{13} \mathrm{C}$ NMR and SEC. azidomethylstyrene) copolymer (4)

Herein is described the general procedure to prepare a P(S-stat-4-AMS) block containing 5 mol. \% 4-azidomethylstyrene in the hydrophobic segment of the block copolymer. In a $100 \mathrm{~mL}$ Schlenk tube, copper (I) chloride $(0.055 \mathrm{~g}, 0.55 \mathrm{mmol})$ and PMDETA $(0.14 \mathrm{~g}, 0.83 \mathrm{mmol})$ were mixed to form the catalytic complex using toluene as solvent ( $5 \mathrm{~mL}$ ). After $15 \mathrm{~min}$, the PLA macroinitiator (2) (4.61 g) dissolved in $15 \mathrm{~mL}$ toluene was added to the reaction flask. Then, 4-azidomethylstyrene $(0.54 \mathrm{~g}, 3.4$ $\mathrm{mmol})$ diluted in styrene $(6.26 \mathrm{~g}, 60.2 \mathrm{mmol})$ and $15 \mathrm{~mL}$ toluene were successively added to the reaction mixture. Upon homogenization of the reaction mixture, it was submitted to three freezepump-thaw cycles, placed into an oil bath at $90{ }^{\circ} \mathrm{C}$ so as to trigger the polymerization and stirred at this temperature for $8 \mathrm{~h}$. At the end of the reaction, the solution was concentrated under vacuum, dissolved in $\mathrm{CHCl}_{3}$, and passed through a pad of silica to remove the copper catalyst. The polymer solution was concentrated and precipitated into a large volume of methanol. This operation was repeated 2-3 times to remove totally unreacted monomer. After the pure polymer was vacuumdried, it was analyzed by ${ }^{1} \mathrm{H} N M R,{ }^{13} \mathrm{C} N M R$, and SEC. 


\subsection{General procedure for the diblock copolymer triazole functionalization (5)}

In a $50 \mathrm{~mL}$ round-bottom flask, copper (I) bromide $(0.011 \mathrm{~g}, 0.077 \mathrm{mmol})$, PMDETA (0.013 g, 0.077 $\mathrm{mmol})$ and toluene $(10 \mathrm{~mL}$ ) were mixed. In a second $50 \mathrm{~mL}$ round-bottom flask, the synthesized copolymer ( $1.0 \mathrm{~g}, 0.077 \mathrm{mmol})$ and 4-ethynyltoluene $(0.05 \mathrm{~g}, 5.5 \mathrm{mmol})$ were mixed and dissolved in $5 \mathrm{~mL}$ toluene, the resulting solution was transferred via a cannula into the reaction flask containing the catalyst under inert atmosphere. The reaction mixture was stirred for $24 \mathrm{~h}$ at room temperature $\left(\sim 25^{\circ} \mathrm{C}\right)$. Afterward, the reaction mixture was passed through a pad of silica to remove the copper catalyst, and the functionalized polymer was precipitated in a large volume of methanol. The functionalized polymer, obtained as a powder $(0.64 \mathrm{~g}, 65 \%$ yield $)$, was vacuum-dried and analyzed by ${ }^{1} \mathrm{H}$ NMR, ${ }^{13} \mathrm{C}$ NMR, and FT-IR.

\subsection{Mechanical orientation of diblock copolymer matrices}

A stainless-steel channel die was used to help the phase separation to occur and thus obtain oriented nanodomains in the different copolymers. Further characteristics of this device can be found in a previous report. [15] Briefly, a small amount of previously pressed copolymer film was placed in the channel die between two stripes of Teflon. The channel die was heated at $120^{\circ} \mathrm{C}$ in a hydraulic press and subjected to constant pressure load for $1 \mathrm{~h}$. Afterward, the channel die was annealed in a vacuum oven at $160{ }^{\circ} \mathrm{C}$ overnight.

\subsection{Solvent vapor annealing orientation of diblock copolymers}

A few drops of diblock copolymer solution (concentration of $20 \mathrm{mg} \cdot \mathrm{mL}^{-1}$ in dichloromethane) were deposited onto a small silicon wafer surface (approximately $1 \mathrm{~cm}^{2}$ ) and spin-coated at $400 \mathrm{rpm}$ for $15 \mathrm{sec}$ and $2000 \mathrm{rpm}$ for $40 \mathrm{sec}$. The obtained thin films were vacuum-dried prior to the annealing. The supported thin films were later placed inside a closed glass chamber and exposed to solvent vapors of tetrahydrofuran for different periods of time. Samples were vacuum-dried prior to SEM observations.

\subsection{Selective hydrolysis of PLA block in oriented block copolymer thin films}


1 The oriented PLA block was removed using a $3 \mathrm{M} \mathrm{NaOH}$ aqueous solution. Experimentally, the

2 specimen sample was immersed in the alkaline solution at $60{ }^{\circ} \mathrm{C}$ and gently shaken on an orbital

3 shaking plate. The hydrolysis reaction times were very different depending on the morphology of

4 the samples: overnight for the thin films prepared on silicon wafer surfaces and almost one month

5 for the parallelograms obtained by mechanical orientation through channel die processing. Once

6 hydrolysis was completed, the samples were rinsed successively with water and ethanol before

7 vacuum-drying overnight and further observation by SEM.

9 2.10. Instrumentation

10 The ${ }^{1} \mathrm{H}$ and ${ }^{13} \mathrm{C}$ NMR studies were realized on a Bruker Avance III spectrometer $(500 \mathrm{MHz}$ and 125

$11 \mathrm{MHz}$, respectively) in $\mathrm{CDCl}_{3}$ with TMS as an internal standard. FT-IR spectra were recorded on a 12 Nicolet Magna-IR 550 spectrometer using the attenuated total reflection (ATR) and $\mathrm{KBr}$ sample 13 holder, between 4000 and $450 \mathrm{~cm}^{-1}$, with an average of 32 consecutive scans and a resolution of 4 $14 \mathrm{~cm}^{-1}$. Size Exclusion Chromatography (SEC) analyses were performed on a system equipped with a 15 Spectra-Physics P100 pump, two PL gel $5 \mu \mathrm{m}$ mixed-C columns (Polymer Laboratories), and a Shodex 16 RI 71 refractive index detector along with a Wyatt Technologies eight-angle laser light scattering 17 (LLS) detector. The eluent was THF at a flow rate of $1 \mathrm{~mL} \cdot \mathrm{min}^{-1}$. Calibration curves for the RI detector were obtained with polystyrene standards from Polymer Labs (PS standards in the range of 13501,997,000 Da). Scanning Electron Microscopy (SEM) was performed on a MERLIN microscope from

20 Zeiss equipped with InLens and SE2 detectors using a low accelerating tension (2-3 kV) with a 21 diaphragm aperture of $30 \mu \mathrm{m}$. Field Emission SEM was performed on a JEOL JSM 7401F coupled 22 with an energy dispersive X-ray (EDX) detector. The samples were first coated with a 4-nm thin layer 23 of palladium/platinum alloy in a Cressington 208 HR sputter-coater. Thermal analyses were realized 24 on a calorimeter model 9105 from TA Instruments. 


\section{Results and Discussion}

\subsection{Synthetic pathway}

Inserting chemical functions of interest at the pore surface of polymer-based membranes is often a challenging task and is mainly driven by the synthetic strategy implemented to prepare the precursor block copolymers. Azide moieties seem to be chemical functionalities of choice to introduce chemical grafts on the pending chains of a (co)polymer through further postpolymerization modification via the well-known copper-catalyzed azide-alkyne cycloaddition (CuAAC) reaction, a so-called "click" reaction. Such a versatile chemical reaction has hitherto been widely applied in polymer chemistry for easy and straightforward functionalization of various natural or synthetic macromolecules, either on pending chains or on termini of the backbone, as reported by different reviews. [35-37] The CUAAC reaction indeed allows for the formation of triazolyl groups, well-known as metal cations scavengers, as they allow for the formation of coordination bonds with diverse oxidized metallic species. To that extent, a certain number of examples dealing with 4-azidomethylstyrene-based homo- or copolymer materials has been reported in the recent literature to design such azido-functionalized macromolecular structures/materials. [38-48] These macromolecular materials can be engaged in CuAAC reaction with various alkynes to produce the corresponding triazolyl-containing (co)polymers. Such materials can present some interesting coordination properties with metallic ions. Such homo- or copolymers in which are embedded 4-AMS can be obtained from the (co)polymerization of 4chloromethylstyrene (4-CMS) and further azidation of the corresponding (co)polymers. [38-42, 4547] Another alternative relies on the direct (co)polymerization of 4-AMS. [43-44, 48] This functional monomer can be homo- or copolymerized in the presence of other monomer, e.g. $(2,3,4,5,6$ pentafluoro)styrene. The proposed synthetic route (Figure 1) followed in this work entails the preparation of a poly(D,L-lactic acid) (PLA) macroinitiator (2) from a heterobifunctional initiator (1) containing both a terminal tertiary $\alpha$-bromoester and a primary alcohol function. The latter should allow for the controlled ring-opening polymerization of $D, L$-Lactide. In contrast, the $\alpha$-bromoester moiety should allow for the polymerization of the second block, namely a poly(styrene-stat-4azidomethylstyrene) (P(S-stat-4-AMS)) (4), via Atom Transfer Radical Polymerization (ATRP) methodology from PLA macroinitiator (2). Finally, the post-polymerization functionalization of the as-prepared isolated diblock copolymers was assessed by CuAAC reaction, [49] to afford the 
corresponding triazolyl containing macromolecular materials (5a) or (5b), depending on the alkyne grafted.

\subsection{Synthesis of initiator (1) (HEBI) and PLA macroinitiator (2)}

Heterobifunctional initiator 2-hydroxyethyl-2-bromoisobutyrate (1) (HEBI) was selected as the starting initiator to prepare the functional diblock copolymers through two successive polymerization reactions. Indeed, this molecule contains a terminal tertiary $\alpha$-bromoester, commonly used as ATRP initiator in styrene polymerization, [50] and another hydroxyl terminus that can promote the ring-opening polymerization (ROP) of $D, L$-lactide in the presence of a metal-based catalyst, i.e. SnOct 2 . According to the reported method, HEBI was synthesized and characterized by spectroscopic techniques to ensure its chemical structure. [34] Afterward, SnOct 2 -catalyzed synthesis of poly(D,L-lactic acid) (PLA) from HEBI initiator and D, L-lactide monomer was achieved at $110{ }^{\circ} \mathrm{C}$ in a microwave reactor for $5.5 \mathrm{~h}$ under moisture-free conditions. The experimental molar masses calculated by ${ }^{1} \mathrm{H}$ NMR were close to those theoretically expected, i.e. 8.0 and $15.0 \mathrm{~kg} . \mathrm{mol}^{-1}$, as shown in Table 1, thus demonstrating the good control of the ROP process. The PLA macroinitiator was purified by precipitation in a mixture hexane/diethyl ether, and the molar mass given by size exclusion chromatography (SEC) equipped with an eight-angle laser light scattering (LLS) detector. The molar mass distribution $(\Theta)$ was also given by SEC, while the functionalization degree was determined by ${ }^{1} \mathrm{H}$ NMR (Figure 2). The ${ }^{1} \mathrm{H}$ NMR spectrum of the vacuum dried product (2), shown in Figure 2, clearly demonstrated that the ROP of D,L-lactide from HEBI was successful. Characteristic PLA signals were observed, notably those with chemical shifts $\delta \sim 5.2$ and $1.6 \mathrm{ppm}$ for methine and methyl groups, respectively, together with those from the HEBI initiator, notably the 4 methylene protons at $\delta \sim 4.5 \mathrm{ppm}$. Additionally, a singlet at $\delta \sim 1.95 \mathrm{ppm}$ was assigned to the six protons of the two equivalent methyl groups from the initiator in $\alpha$-position of the bromine. The ultimate lactide unit inserted in the PLA block during ROP, was identified in the ${ }^{1} \mathrm{H}$ NMR spectrum with protons at $\delta=5.05 \mathrm{ppm}$ and at $\delta=1.68 \mathrm{ppm}$, again assigned to the methine and methyl end group, respectively.

\subsection{Synthesis of 4-azidomethylstyrene (4-AMS) (3)}


4-azidomethylstyrene (4-AMS) (3) was obtained by nucleophilic substitution of chlorine from 4chloromethylstyrene by sodium azide in acetone, as already reported elsewhere. [51] Viscous orange liquid was obtained after evaporation of the acetone and isolated with nearly quantitative yield (98\%). FT-IR spectroscopy (Figure S1 in Supplemental Information) confirmed the presence of the targeted compound with the appearance of a stretching absorption band $\mathrm{v}_{\mathrm{C}-\mathrm{N}_{3}}=2090 \mathrm{~cm}^{-1}$, characteristic of the azide group covalently attached to the benzylic carbon. In addition, ${ }^{1} \mathrm{H} N M R$ spectrum of the pure product (Figure S2 in Supplemental Information) exhibited the shift of the singlet resonance peak of methylene protons in $\alpha$-position of the chlorine from $\delta=4.61 \mathrm{ppm}$ to a new singlet resonance peak at $\delta=4.26 \mathrm{ppm}$ in agreement with the chemical shift of the methylene protons that are now in $\alpha$-position of the azide moiety, a less electron withdrawing group than the halogen. ${ }^{13} \mathrm{C}$ NMR also corroborated these findings; a displacement of the chemical shift of the benzylic carbon was observed from 46.1 to 54.6 ppm, (Figure S3 in Supplemental Information), thus demonstrating the success of the nucleophilic substitution reaction. Mass spectrometry analysis (Figure S4 in Supplemental Information) indicated the presence of a molecular ion mass $[\mathrm{M}]^{+\bullet}=$ $116.9 \mathrm{~m} / \mathrm{z}$ which confirmed the chemical structure of 4-azidomethylstyrene. This latter was stored in a glove box at $-30^{\circ} \mathrm{C}$, due to its high reactivity.

\subsection{Preliminary studies on styrene/4-azidomethylstyrene copolymerization from PLA macroinitiator}

The preparation of diblock statistical copolymers from the PLA macroinitiator (2), styrene and 4AMS was investigated. The synthesis of P(S-stat-4-AMS) (4) was assessed through a typical ATRP methodology. Hence, the copolymerization reaction of the 34 mol. \% 4-AMS with styrene was performed in toluene using PMDETA/CU (I) catalytic complex. The polymerization feed was kept at $100{ }^{\circ} \mathrm{C}$ for $20 \mathrm{~h}$. After purification of the polymer by successive precipitations in methanol and vacuum-drying, the product was isolated as a light-yellow powder with $92 \%$ conversion, as calculated by gravimetric analysis. Upon dissolution of the PLA-b-P(S-stat-4-AMS) (4) diblock copolymer with chloroform, the copper-based catalyst was removed by passing the solution through a pad of silica. Nonetheless, larger solvent amounts were required to dissolve the product, despite this, a gel-like product was unexpectedly observed. $500 \mathrm{MHz}{ }^{1} \mathrm{H}-\mathrm{NMR}$ analysis of the gel through a high-resolution magic angle spinning (HR-MAS) probe exhibits a resonance peak at $9.2 \mathrm{ppm}$ which was assigned to an aldehyde proton. It was assumed that this type of products could arise from the redox reaction of the azide group with the PMDETA-copper (I) complex, involving some $\mathrm{N}_{2}$ release 
1 and leading to the formation of an imine group that can be further hydrolyzed to the corresponding

2 aldehyde moiety. [52] Hence, we stated that the copper (I) complex could promote the reduction of

3 the azide group and an aldehyde molecule could be produced, as depicted in Figure S5

4 (Supplemental Information). We thus hypothesized that 4-AMS generates free radicals by releasing

$5 \quad \mathrm{~N}_{2}$ gas, [53] the nitrene radicals may be capable of initiating the polymerization by itself and

6 therefore, promoting the crosslinking with other growing chains in a non-controlled fashion.

7 Consequently, gel formation may be promoted by an excess of radical species in the reaction

8 medium: chain growing radicals and in situ formation nitrene radicals. It is likely that some of these

9 nitrene radicals were accessible to react with the catalytic copper complex (CU-L-X) and further yield

10 aldehyde groups. To prove the extent of interactions between azide groups and other reagents

11 employed in the ATRP polymerization, a kinetic study was performed. For such experiments, a 4AMS/styrene molar ratio comprised between 5/95 to 34/66 and time lapses between 1 and $24 \mathrm{~h}$ were considered, while the temperature was kept constant at $90{ }^{\circ} \mathrm{C}$ (see Table $\mathbf{S 1}$ in Supplemental Information). Monomer conversion and gel content were routinely calculated and monitored, respectively. It was found out that higher amounts of 4-AMS were incorporated in the polystyrene chain when the initial 4-AMS/styrene molar fraction was lower than 0.15 and when the reaction time did not exceed $10 \mathrm{~h}$. Under these specific experimental conditions, no gel formation was observed.

\subsection{Preparation of PLA-b-PS and PLA-b-P(S-stat-4-AMS) copolymers (4)}

Once the PLA macroinitiator was obtained, the tertiary $\alpha$-bromo ester group capping one terminus of the polymer chain was used as a classic ATRP initiator. The PLA volume fraction $\left(f_{\text {PLA }}\right)$ targeted for such PS- $b$-PLA diblock copolymers was close to 0.35 since a hexagonally packed morphology is generally promoted after phase segregation in this case. However, it is also important to consider the 4-AMS/styrene molar ratio which is no longer higher than 0.15 in the stable polymer block. Considering these variable parameters, two sets of PLA macroinitiators were employed for the concomitant ATRP polymerization of styrene and 4-AMS monomers: $\operatorname{PLA}_{126}\left(M_{\mathrm{n} \mathrm{SEC}}=9.3 \mathrm{~kg} \cdot \mathrm{mol}^{-1}\right)$ and $\operatorname{PLA}_{167}\left(M_{\mathrm{n} \mathrm{SEC}}=12.3 \mathrm{~kg} \cdot \mathrm{mol}^{-1}\right)$. For each macroinitiator, styrene degrees of polymerization of 140 and 185 were envisioned to obtain suitable PLA volume fractions, respectively. Moreover, three different 4-AMS/styrene molar ratios, i.e. 0, 0.05 and 0.10, were investigated for each PLA macroinitiator considered. The copolymerization reaction was carried out by dissolving the PLA 
macroinitiator in toluene in the presence of 4-AMS and styrene as the comonomers and PMDETA/Cu(I)Cl as catalyst under stirring at $90^{\circ} \mathrm{C}$ for $10 \mathrm{~h}$ under inert atmosphere. The purification of the resulting copolymer was completed by removing the $\mathrm{Cu}(\mathrm{I}) \mathrm{Cl} / \mathrm{PMDETA}$ catalytic complex by passing the polymerization mixture on a silica column and successive precipitations in a large volume of methanol. The diblock copolymers were characterized by spectroscopic techniques, such as ATR FT-IR and ${ }^{1} \mathrm{H}$ NMR but also thermal analysis and SEC. The molecular features of the as obtained diblock copolymers are gathered in Table 2. Copolymerization of styrene and 4-AMS via ATRP proceeded with high conversions in the $90-100 \%$ range, regardless of the PLA size or initial comonomers/PLA macroinitiator ratio. Additionally, $M_{n}$ SEC values close to the theoretical ones and $\bigoplus$ in the 1.2-1.5 range indicate that chain growth occurs in a controlled fashion. The ${ }^{1} \mathrm{H}$ NMR spectrum of the $\mathrm{PLA}_{126}-b-\mathrm{P}\left(\mathrm{S}_{329}\right.$-stat-4-AMS $\left.{ }_{13}\right)$ diblock copolymer in $\mathrm{CDCl}_{3}$ is shown in Figure 3 . As expected, signals of the aromatic protons characteristic of the styrene and 4-AMS repeating units can be observed at $\delta=7.4-6.3 \mathrm{ppm}$. Particularly, signals at $\delta=7.40$ and $7.26 \mathrm{ppm}$ were assigned to the 4 aromatic protons of the 4-AMS repeating unit. The poly(D,L-lactic acid) repeating unit was identified by the presence of resonance peaks at $5.20(-\mathrm{CH}-)$ and $1.58 \mathrm{ppm}\left(-\mathrm{CH}_{3}\right)$ together with a broad signal at $\delta=4.24 \mathrm{ppm}$, assigned to the benzylic protons in $\alpha$-position of the azide function. The integration of these protons was used to quantify the 4-AMS composition in the P(S-stat-4-AMS) polymer block. Finally, the methylene hydrogens bonded to the oxygen atoms belonging to the initiator, display broad signals in the 3.95-4.11 ppm region. In these sets of experiments, the synthesis of PS- $b$-PLA copolymers with no 4-AMS inserted in the chain was also considered. These materials were used as a reference, and characterization of such polymers was also achieved via ${ }^{1} \mathrm{H}$ NMR. ATR FT-IR analysis of the PLA- $b$-P(S-stat-4-AMS) diblock copolymers (4) (Figure S6 in Supplemental Information) showed characteristic absorption bands for the stretching of the carbonyl group at $\mathrm{v}_{\mathrm{C}=\mathrm{O}}=1750 \mathrm{~cm}^{-1}$, and the bending absorption band at $\delta_{\mathrm{C}-\mathrm{H} \text { aromatic }}=750$ and 700 $\mathrm{cm}^{-1}$ for the aromatic protons of styrene. Finally, the stretching band of the $\mathrm{C}-\mathrm{N}_{3}$ group at $\mathrm{v}_{\mathrm{C}-\mathrm{N} 3}=$ $2094 \mathrm{~cm}^{-1}$ was also observed in the copolymers inserting 4-AMS. The DSC analysis of these diblock copolymers indicated the presence of two glass transition temperatures $\left(T_{\mathrm{g}}\right)$, namely $T_{\mathrm{g} 1}=54.5^{\circ} \mathrm{C}$ and $T_{\mathrm{g} 2}=105{ }^{\circ} \mathrm{C}$ assigned to PLA and PS blocks, respectively (see Table S2 in Supplemental Information). Interestingly, a slight shift of each block $T_{\mathrm{g}}$ values was observed as compared to the theoretical $T_{\mathrm{g}}$ values of their respective homopolymers $\left(T_{\mathrm{g} \text { PLA }}=50^{\circ} \mathrm{C}, T_{\mathrm{g} \text { PS }}=100^{\circ} \mathrm{C}\right)$. It is more likely that azido groups randomly distributed along the PS block may promote Van der Waals interactions with the lactide repeating units due to its intrinsic lability and may alter in consequence the block 
conformation. The molar mass distribution curve of the $\operatorname{PLA}_{126}\left(M_{n \text { SEC }}=9.3 \mathrm{~kg} \cdot \mathrm{mol}^{-1}\right)$ macroinitiator was compared with those of corresponding $\mathrm{PLA}_{126}-b-\mathrm{P}\left(\mathrm{S}_{\mathrm{m}}\right.$-stat-4-AMS $\left.\mathrm{S}_{n}\right)$ copolymers. Figure 4 notably shows that SEC monomodal traces of such block copolymers, e.g. PLA $A_{126}-b-\mathrm{P}\left(\mathrm{S}_{111}-\mathrm{stat}-4-\right.$ $\left.\mathrm{AMS}_{10}\right)$ and $\mathrm{PLA}_{126}-b-\mathrm{P}\left(\mathrm{S}_{97}-\right.$ stat-4-AMS 4$)$, are shifted towards higher molar masses when compared to the corresponding PLA P $_{126}$ macroinitiator (2), as expected from the polymerization of styrene and 4-AMS from the latter. Analogous results (Figure $\mathbf{S 7}$ in the supporting information) were obtained for the PLA ${ }_{167}\left(M_{n \text { SEC }}=12.3 \mathrm{~kg} \cdot \mathrm{mol}^{-1}\right)$ macroinitiator when compared to its corresponding PLA $167-b$ $\mathrm{P}\left(\mathrm{S}_{\mathrm{m}}\right.$-stat-4-AMS $\left.\mathrm{n}\right)$ copolymers after copolymerization of styrene and 4-AMS.

\subsection{Functionalization of diblock copolymers}

The azido groups present along the PS backbone enable the functionalization of the copolymer to afford triazole derivatives (5a) or (5b) via CuAAC between PLA-b-P(S-stat-4-AMS) diblock copolymers and $p$-tolylacetylene or 2-methyl-3-butyn-2-ol, respectively, as depicted in Figure 1. The presence of triazole moieties in the porous polystyrene matrix will enhance its capacity to interact with metallic cations. It is worth mentioning that a different behavior in phase segregation of the triazolyl-functionalized copolymers is expected when compared to non-functionalized counterparts. This phenomenon relies on the presence of 4-AMS repeating units randomly inserted in the polystyrene block, leading to an increment of the polarity in the hydrophobic block. After functionalization, triazole functionalized polymers were obtained after precipitation in methanol and vacuum drying. ${ }^{1} \mathrm{H}$ NMR spectra of the CuAAC-mediated functionalized PLA-b-P(S-stat-4-AMS) diblock copolymers (see Figure 5, for instance) showed the presence of new resonance signals when compared to their copolymer precursors. Indeed, a new broad singlet appeared at $\delta=7.6 \mathrm{ppm}$, ascribed to the aromatic triazolyl proton. Additionally, a clear shift of the signal ascribed to the benzylic protons, previously in $\alpha$-position of the azide groups on the PLA- $b$-P(S-stat-4-AMS), observed from $\delta=4.2$ to $3.5 \mathrm{ppm}$, demonstrated the success of the CuAAC-mediated functionalization of the azido-functionalized diblock copolymer with $p$-tolylacetylene. The functionalization yield was determined by ${ }^{1} \mathrm{H}$ NMR and calculated by comparing the integration of the triazole ring proton at $\delta=7.82 \mathrm{ppm}$ with that of the benzylic methylene protons of the polystyrene block at $\delta=1.92 \mathrm{ppm}$. Table 3 summarizes the so calculated CuAAC-mediated functionalization yields for the obtained copolymers. Furthermore, ATR FT-IR (Figure S6 in Supplemental Information) analysis of the functionalized copolymers did not show the presence of 
1 any characteristic asymmetric stretching band of the $-\mathrm{N}_{3}$ group at $2090 \mathrm{~cm}^{-1}$ upon CuAAC "click"

2 reaction, thus demonstrating the success of the functionalization strategy. Additionally, absorption

3 bands for the stretching band of the carbonyl group at $1750 \mathrm{~cm}^{-1}$, and the bending of $\mathrm{C}-\mathrm{H}$ aromatic bonds at 750 and $700 \mathrm{~cm}^{-1}$ were observed, demonstrating the presence of lactide and styrene in the copolymer and thus no degradation during the CUAAC reaction.

\subsection{Macroscopic orientation of functional copolymers and pore generation}

8 The prepared diblock copolymers (5a-b) have specific features to assist microphase segregation and further promote a hierarchical array to obtain nanostructured materials. As previously stated, the volume fraction of each block is one of the most important variables, and it has been previously reported that for PS- $b$-PLA copolymers, an asymmetric phase is preferable. To develop PLA cylinders within a PS matrix, values of PLA volume fraction $\left(f_{\mathrm{PLA}}\right)$ must be equal to approximately 0.35 . [34]

13 For all synthesized block copolymers, $f_{\text {PLA }}$ was calculated according to the molar mass given by ${ }^{1} \mathrm{H}$ 14 NMR spectroscopy. These block dimensions should enhance phase segregation towards a 15 hexagonally close packed morphology, after the alignment of PLA domains in the PS matrix. We implemented two different orientation techniques to promote mesoscopic order in the copolymer matrix. The first technique relied on the mechanical orientation of the sample in solid state, thus obtaining a parallelepiped due to shear stress applied to a pre-oriented film of the copolymer in a confined space (i.e., channel die). Theoretically, the stress applied to the copolymer forced the chains to rearrange into a higher ordered conformation, shifting the system towards its most stable structure. After PLA hydrolysis, a nanoporous morphology of the resulting material could be observed, as depicted in Figure $\mathbf{S 8}$ (Supplemental Information), for the SEM image of a porous $\mathrm{P}\left(\mathrm{S}_{329^{-}}\right.$ stat-4-AMS ${ }_{13}$ ) sample. Pore sizes of around $100 \mathrm{~nm}$ were detected. The second technique employed consisted in the orientation of the copolymer phases promoted by the swelling effect undergone in the presence of solvent vapors. SEM images showed the formed cavities in the functional polystyrene surface, after PLA alkaline hydrolysis (Figure 6 and Figure 7). Overall, pore formation was clearly observed; however, the magnitude of pore sizes was higher than that obtained with the channel die technique. Indeed, pore sizes in the range of $100 \mathrm{~nm}$ to $1 \mu \mathrm{m}$ were detected. Such broad the copolymer precursors. 


\section{4. Conclusions}

2 We have developed a new synthetic route to obtain functional diblock copolymers by utilizing a 3 heterobifunctional ROP-ATRP initiator, i.e. 2-hydroxyethyl-2-bromoisobutyrate (HEBI). A poly(D,L4 lactic acid) macroinitiator was synthesized possessing a tertiary carbon-bromine end-group. Further 5 copolymerization of 4-azidomethylstyrene (4-AMS) and styrene from PLA-Br macroinitiator was 6 successfully carried out to generate the second azido-functionalized polystyrene block (P(S-stat-47 AMS)). Better copolymerization results were obtained with a 90/10: styrene/4-azidomethylstyrene 8 molar ratio. Subsequent CuAAC reaction of the azide pending groups on the polymer backbone with

9 two acetylenes was carried out, affording the resulting triazolyl functionalized copolymers with high 10 functionalization yield. The 4-(azidomethyl) group present in the polystyrene block slightly shifted 11 the PLA and PS glass transition temperatures toward lower values compared with the reference PLA$12 \quad b$-PS block copolymers.

13 Upon macroscopic orientation and subsequent alkaline hydrolysis of the PLA block, triazolyl14 containing porous polystyrenes were formed with varying pore sizes depending on the orientation 15 technique used for the copolymer precursors. This straightforward approach paves the way to the 16 versatile generation of functional porous polystyrene frameworks with tunable functionality via 17 "click" chemistry.

19 Acknowledgments

20 The authors gratefully acknowledge financial support from the National Council of Science and 21 Technology (CONACYT-México, grant \#256727) as well as from CNRS and Univ Paris Est Creteil 22 (France). They also thank Q. Jorge Felix Espinosa, M.Sc. J. Guadalupe Télles, and M.Sc. Maria del 23 Rosario Rangel from CIQA for their technical assistance in the laboratory. 


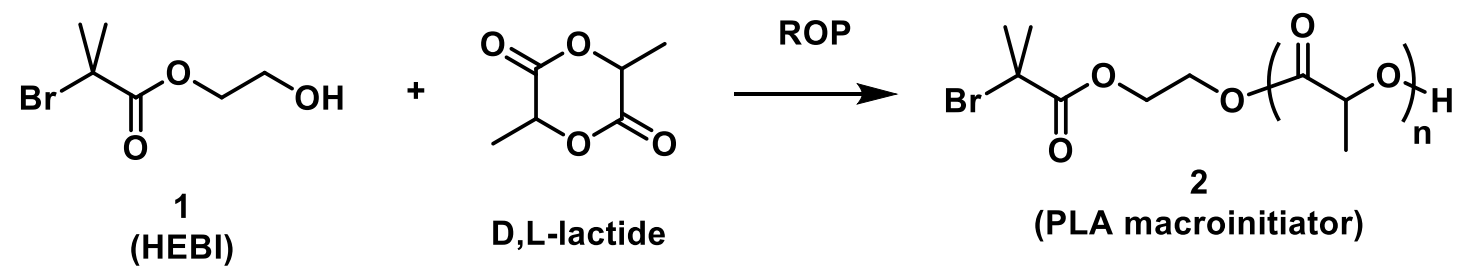

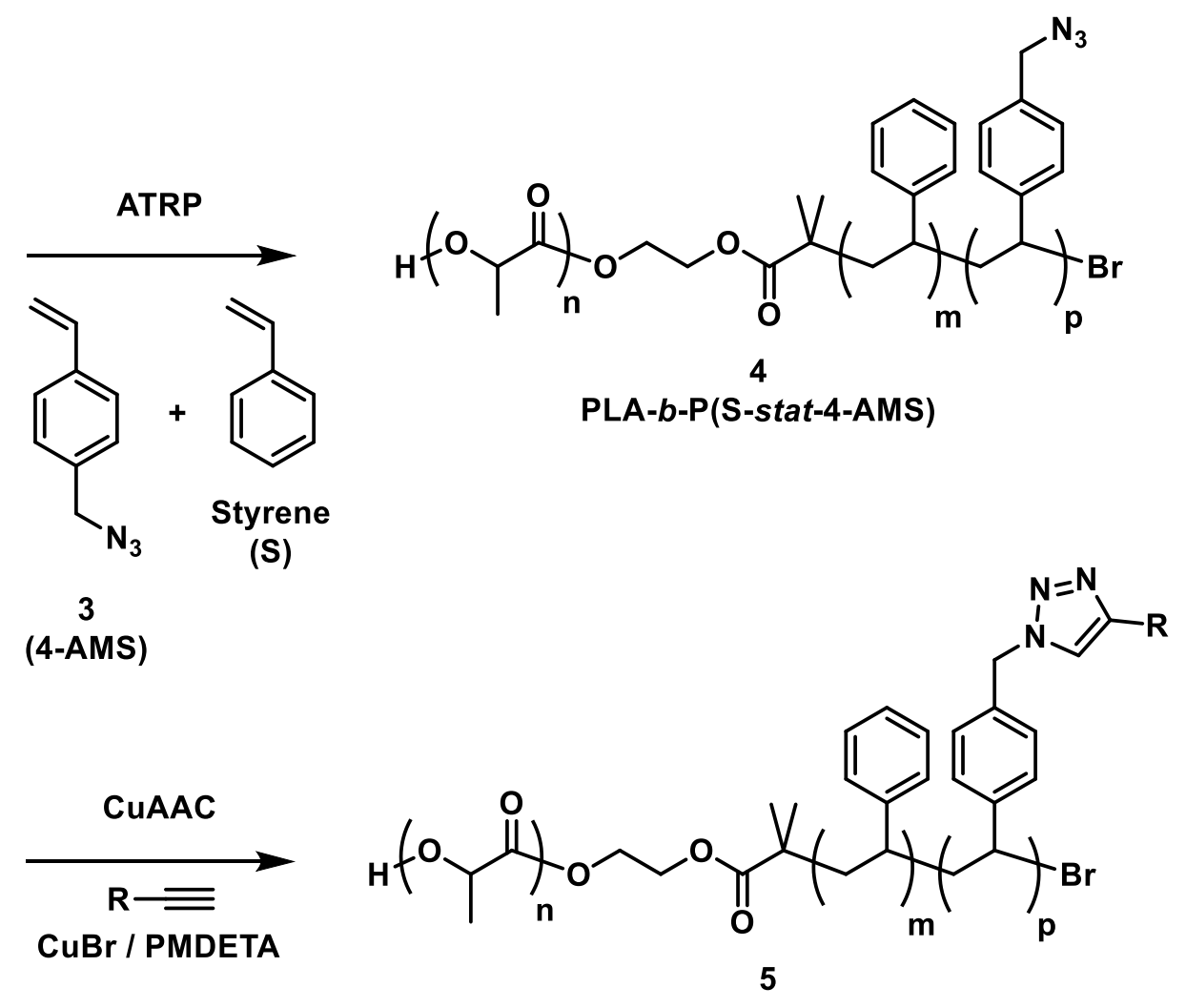

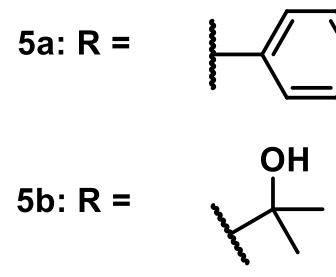

2 Figure 1 Synthetic route applied for the preparation of PLA-b-P(S-stat-4-AMS) azido functionalized 3 diblock copolymers. 

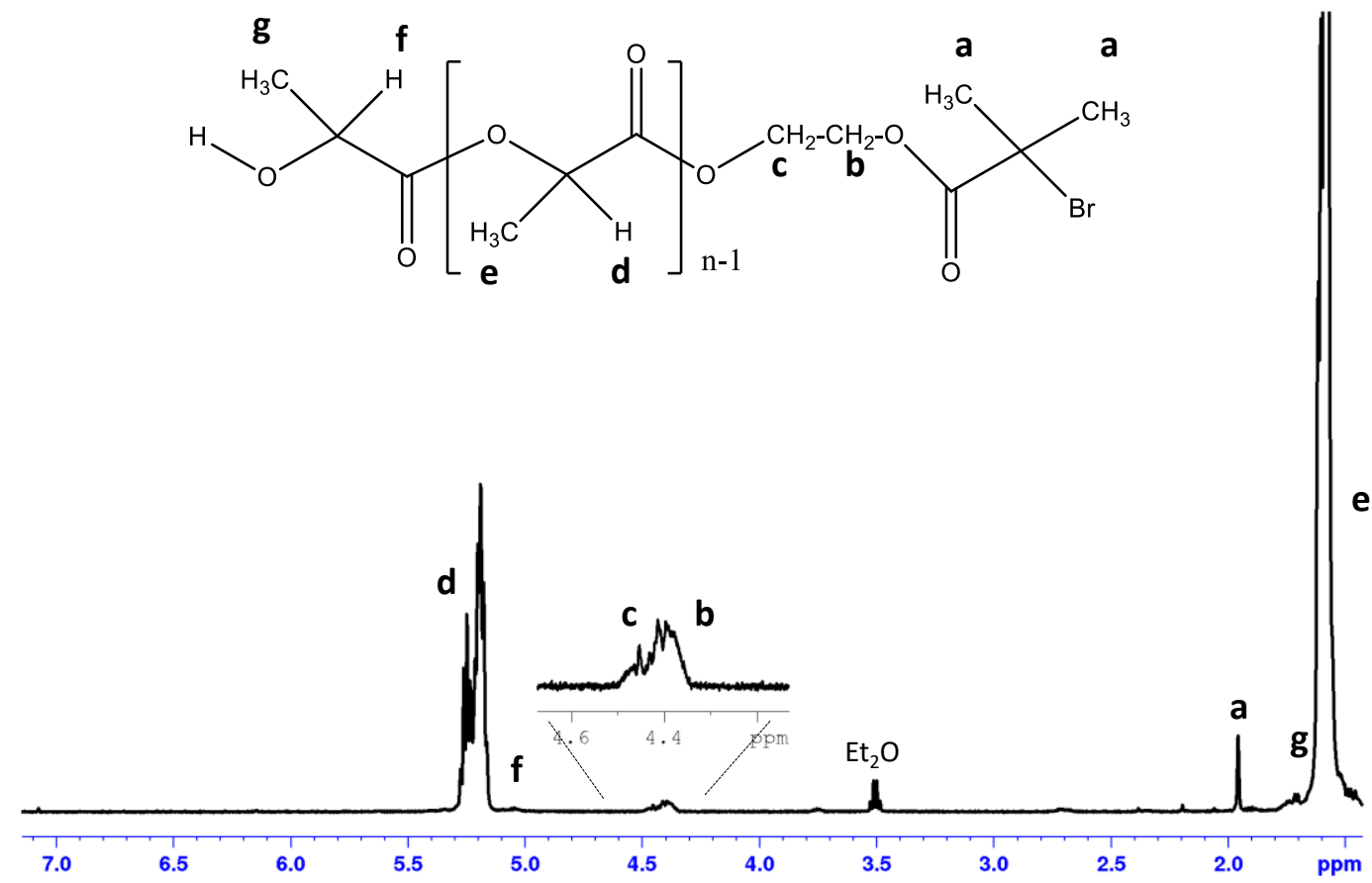

1

2 Figure 2. ${ }^{1} \mathrm{H}$ NMR spectrum of PLA macroinitiator (2) in $\mathrm{CDCl}_{3}$. 


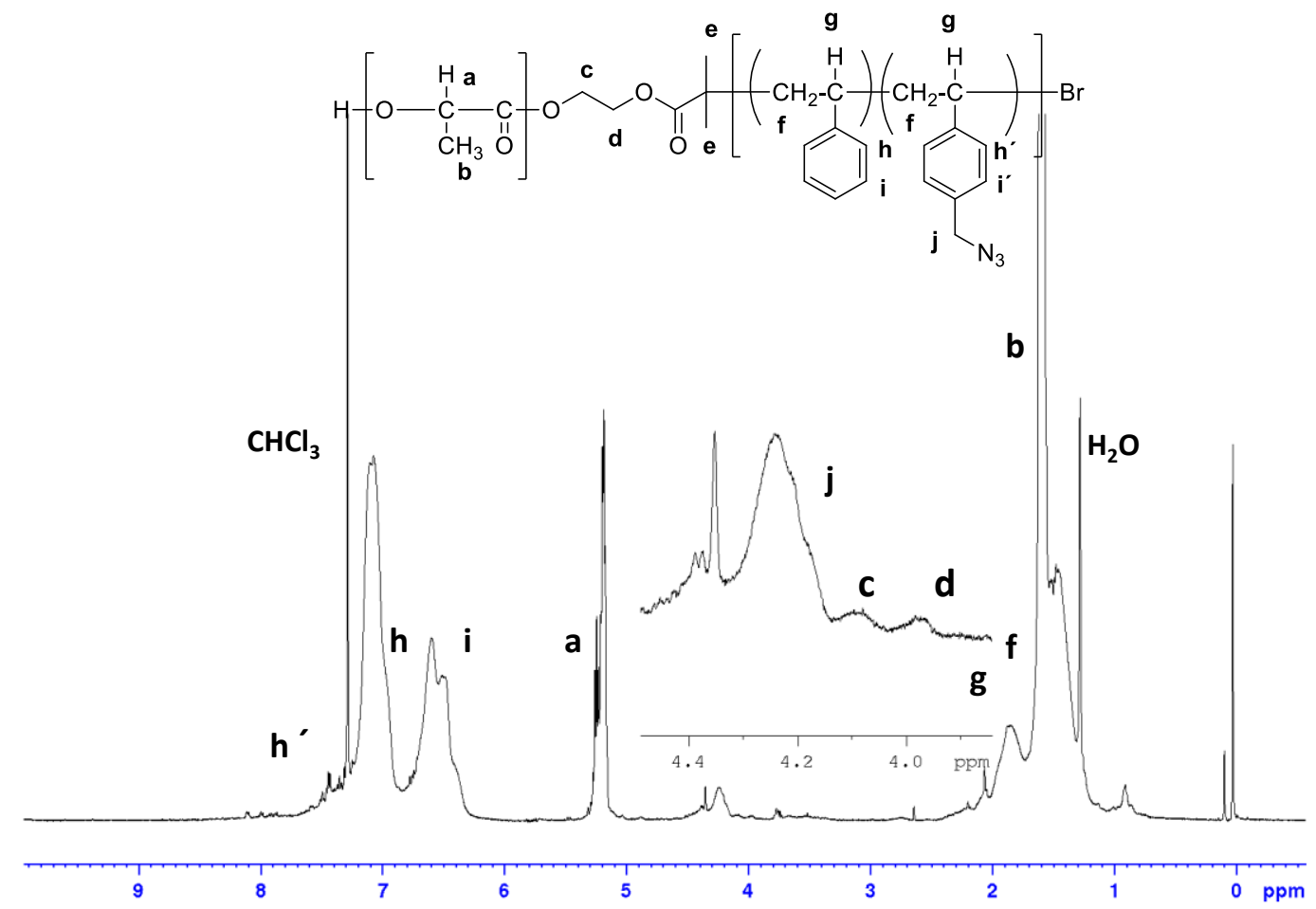

1

Figure 3. ${ }^{1} \mathrm{H}$ NMR spectrum of $\mathrm{PLA}_{126}-b-\mathrm{P}\left(\mathrm{S}_{111}\right.$-stat-4-AMS 10$)(4)$ in $\mathrm{CDCl}_{3}$. 


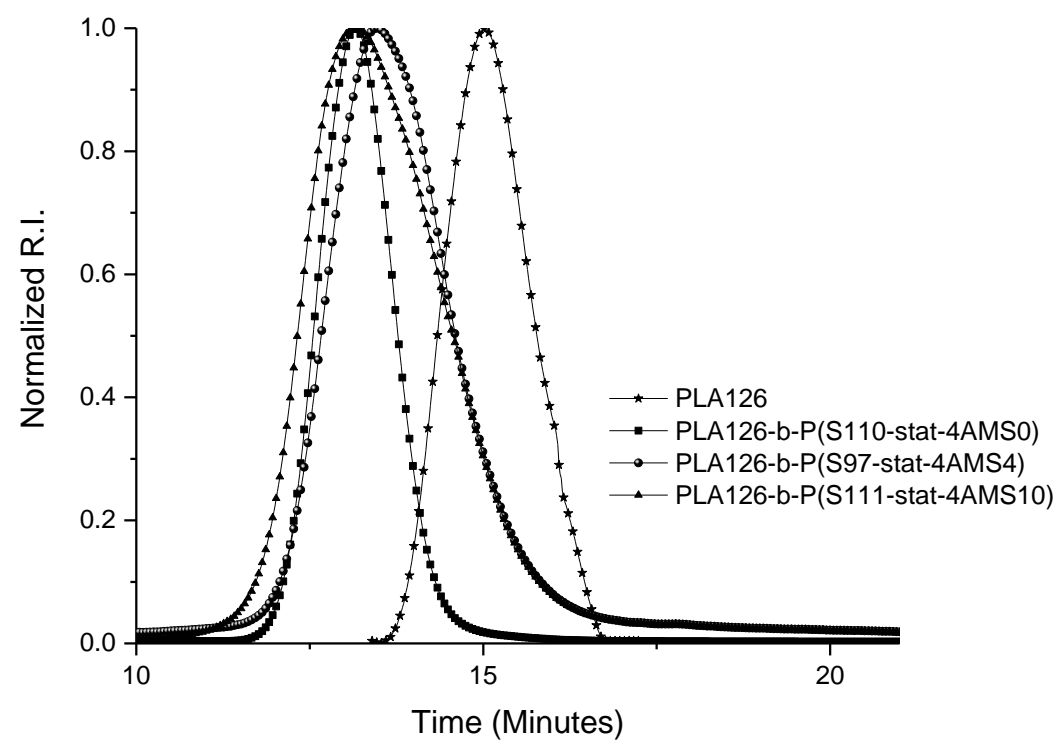

1

2 Figure 4. Size exclusion chromatographic traces of synthetized $\mathrm{PLA}_{126}$ macroinitiator and 3 corresponding $\mathrm{PLA}_{126}-b-\mathrm{P}\left(\mathrm{S}_{\mathrm{m}}\right.$-stat-4-AMS $\left.\mathrm{p}\right)$ block copolymers.

4 


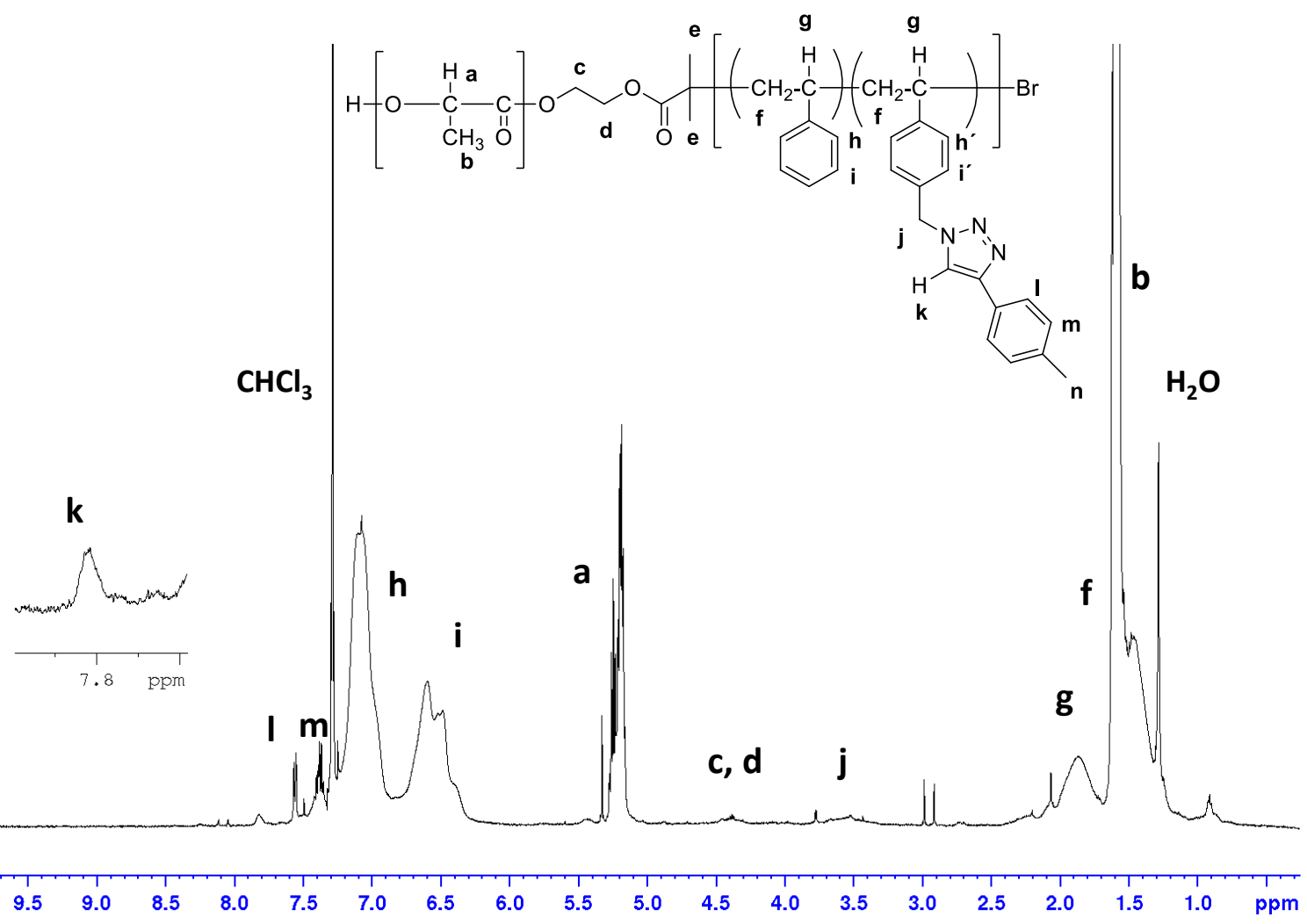

1

2

3 tolylacetylene.

4

5

6

7

8

9

10

11

12

13 
1
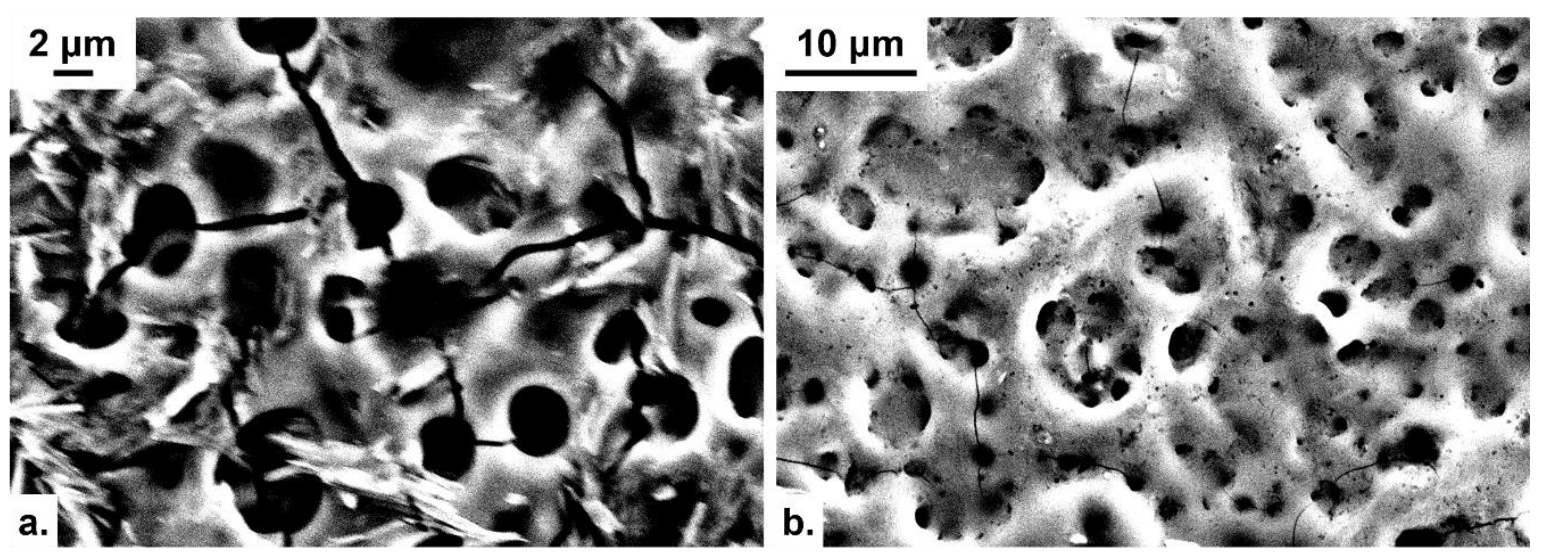

3 Figure 6. SEM micrograph of porous $\mathrm{P}\left(\mathrm{S}_{111}\right.$-stat-4-AMS $\left.\mathrm{S}_{10}\right)$ thin film sample. 

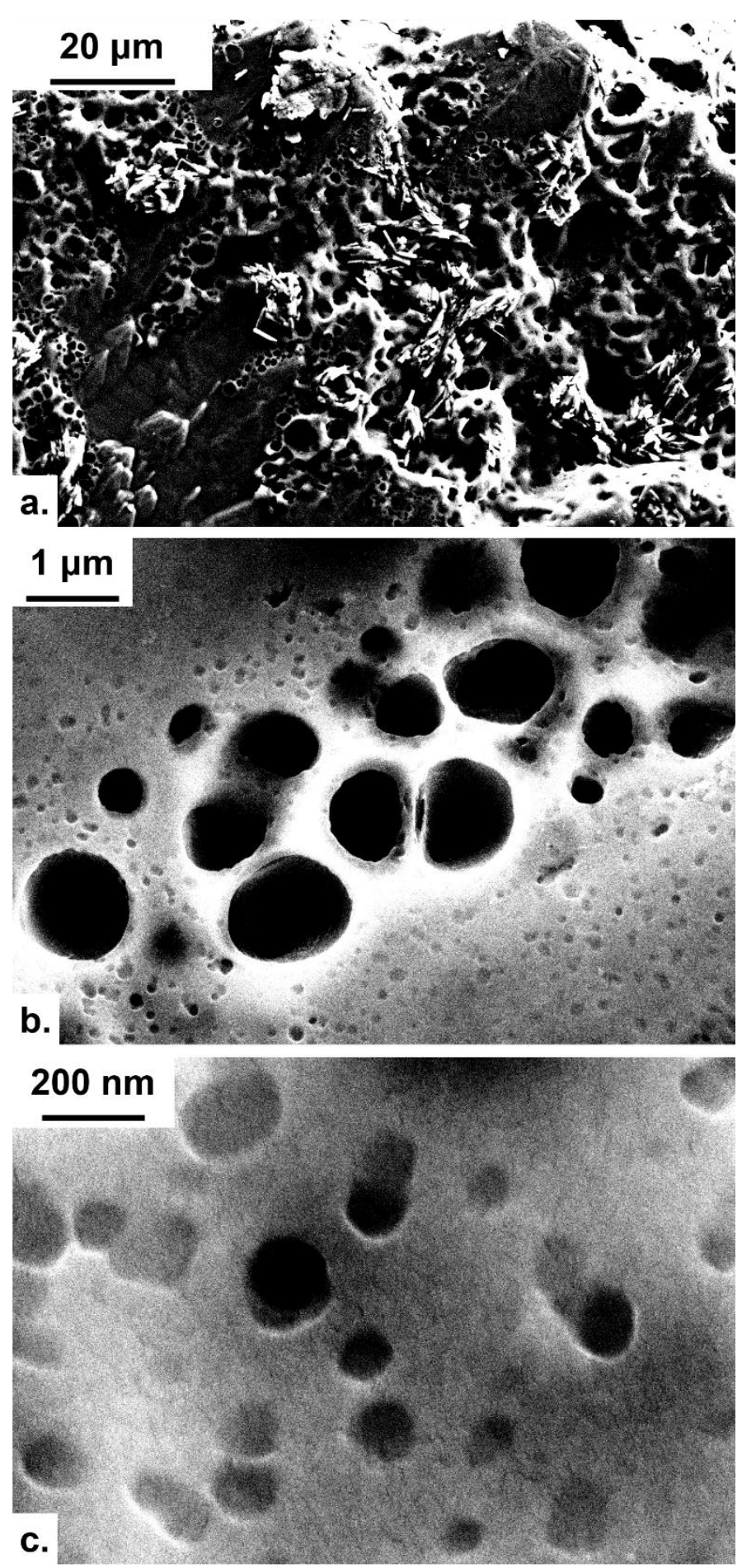

2 Figure 7. SEM micrograph of porous $\mathrm{P}\left(\mathrm{S}_{152}\right.$-stat-4-AMS $\left.\mathrm{S}_{10}\right)$ thin film sample. 
1 Table 1. Molecular features of synthesized poly(D,L-lactic acid) macroinitiators.

\begin{tabular}{|c|c|c|c|c|c|c|}
\hline $\operatorname{PLA}_{n}{ }^{a}$ & $\begin{array}{l}\text { Conv. }{ }^{b}( \\
\%)\end{array}$ & $\begin{array}{c}M_{\mathrm{n} \text { theor }}{ }^{\mathrm{c}} \\
\left(\mathrm{kg} \cdot \mathrm{mol}^{-1}\right)\end{array}$ & $\begin{array}{c}M_{\mathrm{n} \mathrm{NMR}}{ }^{d} \\
\left(\mathrm{~kg} \cdot \mathrm{mol}^{-1}\right)\end{array}$ & $\begin{array}{c}M_{\mathrm{n} \mathrm{SEC}}{ }^{e} \\
\left(\mathrm{~kg} \cdot \mathrm{mol}^{-1}\right)\end{array}$ & $\boldsymbol{\theta}^{e}$ & $\begin{array}{l}\mathrm{F}^{f} \\
(\%)\end{array}$ \\
\hline $\operatorname{PLA}_{1}$ & 91 & 7.2 & 8.2 & 9,300 & 1.54 & 97 \\
\hline $\mathrm{PLA}_{167}$ & 93 & 14.0 & 14.8 & 12,300 & 1.50 & 96 \\
\hline
\end{tabular}

$2 \quad{ }^{a} \mathrm{n}$ : number-average polymerization degree of PLA as determined by ${ }^{1} \mathrm{H} N M R$.

$3{ }^{b}$ Conversion as determined by gravimetry.

$4{ }^{c} M_{n}$ theor $=$ conversion $\times \mathrm{DP}_{\mathrm{n}} \times \mathrm{M}_{0}$ (Lactide).

$5 \quad{ }^{d} M_{\mathrm{nNMR}}$ : number-average molar mass as evaluated by ${ }^{1} \mathrm{H}$ NMR.

$6{ }^{e}$ Values from SEC/LLS measurements with PS standards.

$7 \quad{ }^{f}$ End-group functionality as determined by ${ }^{1} \mathrm{H}$ NMR.

8

9 Table 2. Molecular features of synthesized $\mathrm{PLA}_{\mathrm{n}}-b-\mathrm{P}\left(\mathrm{S}_{\mathrm{m}}\right.$-stat-4-AMS $\left.\mathrm{S}_{\mathrm{p}}\right)$ diblock copolymers.

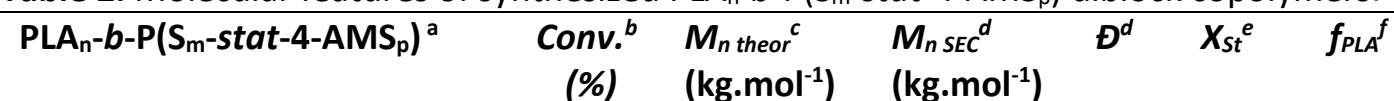

\begin{tabular}{|c|c|c|c|c|c|c|}
\hline $\mathrm{PLA}_{126}-b-\mathrm{P}\left(\mathrm{S}_{110} \text {-stat-4-AMS }\right)_{0}$ & 98 & 19.8 & 20.2 & 1.12 & 1.00 & 0.18 \\
\hline $\mathrm{PLA}_{126}-b-\mathrm{P}\left(\mathrm{S}_{97}-\text { stat-4-AMS }\right)_{4}$ & 92 & 20.2 & 19.9 & 1.51 & 0.96 & 0.40 \\
\hline $\mathrm{PLA}_{126}-b-\mathrm{P}\left(\mathrm{S}_{111}-\right.$ stat-4-AMS $\left.{ }_{10}\right)$ & 92 & 20.5 & 22.3 & 1.35 & 0.91 & 0.36 \\
\hline $\mathrm{PLA}_{167-b-\mathrm{P}}\left(\mathrm{S}_{195-\text { stat-4-AMS }}\right)$ & 90 & 37.1 & 32.8 & 1.21 & 1.00 & 0.33 \\
\hline $\mathrm{PLA}_{167}-b-\mathrm{P}\left(\mathrm{S}_{152}-\right.$ stat-4-AMS 10$)$ & 88 & 37.7 & $28 ; 3$ & 1.38 & 0.93 & 0.38 \\
\hline $\mathrm{PLA}_{167}-b-\mathrm{P}\left(\mathrm{S}_{175}\right.$-stat-4-AMS $\left.{ }_{38}\right)$ & 93 & 38.3 & 36.5 & 1.59 & 0.82 & 0.30 \\
\hline
\end{tabular}

10

11

12

13

14

15

16

17

18

19

20

${ }^{a} \mathrm{n}, \mathrm{m}, \mathrm{p}$ : number-average polymerization degree of PLA and of P(S-stat-4-AMS) blocks as determined by ${ }^{1} \mathrm{H}$ NMR.

${ }^{b}$ Conversion as determined by gravimetry.

${ }^{c} M_{\mathrm{n} \text { theor }}=$ conversion $\times D P_{\mathrm{n}} \times M_{0}$ (styrene) $+M_{\mathrm{n} \text { PLA }}$

${ }^{d}$ Values from SEC/LLS measurements with PS standards.

${ }^{e}$ Styrene molar fraction in the P(S-stat-4-AMS) random block.

${ }^{f}$ PLA volume fraction as determined by ${ }^{1} \mathrm{H}$ NMR, assuming that densities of PS and PLA are 1.02 and $1.25 \mathrm{~g} / \mathrm{mL}$, respectively. 
2 Table 3. Functionalization yields observed for the CuAAC "click" modification of various PLA- $b$-P(S-

3 stat-4-AMS) diblock copolymers with alkyne-appended compounds.

\begin{tabular}{|c|c|c|}
\hline$P L A_{n}-b-P\left(S_{m}-\right.$ stat-4-AMS $\left.S_{p}\right)$ & Alkyne grafted & Functionalization yield $^{a}(\%)$ \\
\hline $\mathrm{PLA}_{126}-b-\mathrm{P}\left(\mathrm{S}_{97}-\right.$ stat-4-AMS $\left.{ }_{4}\right)$ & 2-methyl-3-butyn-2-ol & 85 \\
\hline $\mathrm{PLA}_{126}-b-\mathrm{P}\left(\mathrm{S}_{111}-\right.$ stat-4-AMS 10$)$ & 2-methyl-3-butyn-2-ol & 98 \\
\hline $\mathrm{PLA}_{167-b-\mathrm{P}}\left(\mathrm{S}_{152}\right.$-stat-4-AMS 10$)$ & 2-methyl-3-butyn-2-ol & -- \\
\hline $\mathrm{PLA}_{167}-b-\mathrm{P}\left(\mathrm{S}_{175}-s t a t-4-\mathrm{AMS}_{38}\right)$ & 2-methyl-3-butyn-2-ol & 91 \\
\hline $\mathrm{PLA}_{126}-b-\mathrm{P}\left(\mathrm{S}_{97}-\right.$ stat-4-AMS $\left.{ }_{4}\right)$ & $p$-tolylacetylene & -- \\
\hline $\mathrm{PLA}_{126}-b-\mathrm{P}\left(\mathrm{S}_{111}\right.$-stat-4-AMS $\left.{ }_{10}\right)$ & $p$-tolylacetylene & 97 \\
\hline $\mathrm{PLA}_{167}-b-\mathrm{P}\left(\mathrm{S}_{152}-s t a t-4-\mathrm{AMS}_{10}\right)$ & $p$-tolylacetylene & 97 \\
\hline $\mathrm{PLA}_{167}-b-\mathrm{P}\left(\mathrm{S}_{175}-\right.$ stat-4-AMS 38$)$ & $p$-tolylacetylene & 87 \\
\hline
\end{tabular}

${ }^{a}$ Functionalization yield as calculated by ${ }^{1} \mathrm{H}$ NMR.

4 


\section{References}

(

1. Tan, K. W.; Wiesner, U., Block Copolymer Self-Assembly Directed Hierarchically Structured Materials from Nonequilibrium Transient Laser Heating. Macromolecules 2019, 52 (2), 395-409.

2. Singh, M.; Odusanya, O.; Wilmes, G. M.; Eitouni, H. B.; Gomez, E. D.; Patel, A. J.; Chen, V. L.; Park, M. J.; Fragouli, P.; latrou, H.; Hadjichristidis, N.; Cookson, D.; Balsara, N. P., Effect of Molecular Weight on the Mechanical and Electrical Properties of Block Copolymer Electrolytes. Macromolecules 2007, 40 (13), 45784585.

3. Tan, K. W.; Werner, J. G.; Goodman, M. D.; Kim, H. S.; Jung, B.; Sai, H.; Braun, P. V.; Thompson, M. O.; Wiesner, U., Synthesis and Formation Mechanism of All-Organic Block Copolymer-Directed Templating of Laser-Induced Crystalline Silicon Nanostructures. ACS Applied Materials \& Interfaces 2018, 10 (49), 4277742785.

4. Dorin, R. M.; Marques, D. S.; Sai, H.; Vainio, U.; Phillip, W. A.; Peinemann, K.-V.; Nunes, S. P.; Wiesner, U., Solution Small-Angle X-ray Scattering as a Screening and Predictive Tool in the Fabrication of Asymmetric Block Copolymer Membranes. ACS Macro Letters 2012, 1 (5), 614-617.

5. Radjabian, M.; Abetz, V., Advanced porous polymer membranes from self-assembling block copolymers. Progress in Polymer Science 2020, 102, 101219.

6. Nunes, S. P., Block Copolymer Membranes for Aqueous Solution Applications. Macromolecules 2016, 49 (8), 2905-2916.

7. Nassif, N.; Livage, J., From diatoms to silica-based biohybrids. Chemical Society Reviews 2011, 40 (2), 849-859.

8. Bertrand, A.; Bousquet, A.; Lartigau-Dagron, C.; Billon, L., Hierarchically porous bio-inspired films prepared by combining "breath figure" templating and selectively degradable block copolymer directed selfassembly. Chemical Communications 2016, 52 (61), 9562-9565.

9. Montero de Espinosa, L.; Meesorn, W.; Moatsou, D.; Weder, C., Bioinspired Polymer Systems with Stimuli-Responsive Mechanical Properties. Chemical Reviews 2017, 117 (20), 12851-12892.

10. Yao, P.-F.; Li, H.-Y.; Huang, F.-P.; Yu, Q.; Qin, X.-H.; Tang, J.; Tao, Y.; Bian, H.-D., A series of multidimensional MOFs incorporating a new N-heterocyclic building block: 5,5' -di(pyridin-4-yl)-3,3' bi(1,2,4-triazole). RSC Advances 2015, 5 (60), 48596-48606.

11. Zou, Y.; Zhou, X.; Ma, J.; Yang, X.; Deng, Y., Recent advances in amphiphilic block copolymer templated mesoporous metal-based materials: assembly engineering and applications. Chemical Society Reviews 2020, 49 (4), 1173-1208.

12. Liu, X.; Monzavi, T.; Gitsov, I., Controlled ATRP Synthesis of Novel Linear-Dendritic Block Copolymers and Their Directed Self-Assembly in Breath Figure Arrays. Polymers 2019, 11 (3), 539.

13. Zalusky, A. S.; Olayo-Valles, R.; Wolf, J. H.; Hillmyer, M. A., Ordered Nanoporous Polymers from Polystyrene-Polylactide Block Copolymers. Journal of the American Chemical Society 2002, 124 (43), 1276112773.

14. Ryu, J.-H.; Park, S.; Kim, B.; Klaikherd, A.; Russell, T. P.; Thayumanavan, S., Highly Ordered Gold Nanotubes Using Thiols at a Cleavable Block Copolymer Interface. Journal of the American Chemical Society 2009, 131 (29), 9870-9871.

15. Le Droumaguet, B.; Poupart, R.; Grande, D., "Clickable" thiol-functionalized nanoporous polymers: from their synthesis to further adsorption of gold nanoparticles and subsequent use as efficient catalytic supports. Polymer Chemistry 2015, 6 (47), 8105-8111.

16. Kang, M.; Moon, B., Synthesis of Photocleavable Poly(styrene-block-ethylene oxide) and Its SelfAssembly into Nanoporous Thin Films. Macromolecules 2009, 42 (1), 455-458.

17. Zhao, H.; Gu, W.; Thielke, M. W.; Sterner, E.; Tsai, T.; Russell, T. P.; Coughlin, E. B.; Theato, P., Functionalized Nanoporous Thin Films and Fibers from Photocleavable Block Copolymers Featuring Activated Esters. Macromolecules 2013, 46 (13), 5195-5201. 
18. Gamys, C. G.; Schumers, J.-M.; Vlad, A.; Fustin, C.-A.; Gohy, J.-F., Amine-functionalized nanoporous thin films from a poly(ethylene oxide)-block-polystyrene diblock copolymer bearing a photocleavable onitrobenzyl carbamate junction. Soft Matter 2012, 8 (16), 4486-4493.

19. Goldbach, J. T.; Lavery, K. A.; Penelle, J.; Russell, T. P., Nano- to Macro-Sized Heterogeneities Using Cleavable Diblock Copolymers. Macromolecules 2004, 37 (25), 9639-9645.

20. Goldbach, J. T.; Russell, T. P.; Penelle, J., Synthesis and Thin Film Characterization of Poly(styreneblock-methyl methacrylate) Containing an Anthracene Dimer Photocleavable Junction Point. Macromolecules 2002, 35 (11), 4271-4276.

21. Zhang, M.; Yang, L.; Yurt, S.; Misner, M. J.; Chen, J.-T.; Coughlin, E. B.; Venkataraman, D.; Russell, T. P., Highly Ordered Nanoporous Thin Films from Cleavable Polystyrene-block-poly(ethylene oxide). Advanced Materials 2007, 19 (12), 1571-1576.

22. Yurt, S.; Anyanwu, U. K.; Scheintaub, J. R.; Coughlin, E. B.; Venkataraman, D., Scission of Diblock Copolymers into Their Constituent Blocks. Macromolecules 2006, 39 (5), 1670-1672.

23. Satoh, K.; Poelma, J. E.; Campos, L. M.; Stahl, B.; Hawker, C. J., A facile synthesis of clickable and acidcleavable PEO for acid-degradable block copolymers. Polymer Chemistry 2012, 3 (7), 1890-1898.

24. Poupart, R.; Benlahoues, A.; Le Droumaguet, B.; Grande, D., Porous Gold Nanoparticle-Decorated Nanoreactors Prepared from Smartly Designed Functional Polystyrene-block-Poly(d,I-Lactide) Diblock Copolymers: Toward Efficient Systems for Catalytic Cascade Reaction Processes. ACS Applied Materials \& Interfaces 2017, 9 (37), 31279-31290.

25. Rao, J.; De, S.; Khan, A., Synthesis and self-assembly of dynamic covalent block copolymers: towards a general route to pore-functionalized membranes. Chemical Communications 2012, 48 (28), 3427-3429.

26. Li, Y.; Xu, Y.; Cao, S.; Zhao, Y.; Qu, T.; Iyoda, T.; Chen, A., Nanoporous Films with Sub-10 nm in Pore Size from Acid-Cleavable Block Copolymers. Macromolecular Rapid Communications 2017, 38 (5), 1600662.

27. Glassner, M.; Blinco, J. P.; Barner-Kowollik, C., Formation of nanoporous materials via mild retroDiels-Alder chemistry. Polymer Chemistry 2011, 2 (1), 83-87.

28. Arredondo, J.; Elizalde, L. E.; Le Droumaguet, B.; Grande, D., A new route toward imidazolinefunctionalized porous polymeric materials from corresponding polystyrene-polylactide diblock copolymers. Reactive and Functional Polymers 2016, 104, 62-70.

29. He, Y.; Zhao, F.; Zhang, C.; Abd Ei-Aty, A. M.; Baranenko, D. A.; Hacimüftüoğlu, A.; She, Y., Assessment of magnetic core-shell mesoporous molecularly imprinted polymers for selective recognition of triazoles residual levels in cucumber. Journal of Chromatography $B$ 2019, 1132, 121811.

30. Ji, E.; Pellerin, V.; Ehrenfeld, F.; Laffore, A.; Bousquet, A.; Billon, L., Hierarchical honeycombstructured films by directed self-assembly in "breath figure" templating of ionizable "clicked" PH3T-b-PMMA diblock copolymers: an ionic group/counter-ion effect on porous polymer film morphology. Chemical Communications 2017, 53 (11), 1876-1879.

31. Song, J.; Cho, B. K., Mesoporous Polystyrenes via Lamellar Block Copolymer Assembly. Bulletin of the Korean Chemical Society 2013, 34 (1), 23-24.

32. Matyjaszewski, K., Atom Transfer Radical Polymerization (ATRP): Current Status and Future Perspectives. Macromolecules 2012, 45 (10), 4015-4039.

33. Armarego, W. L. F.; Perrin, D. D., Purification of Laboratory Chemicals. Butterworth-Heinemann: Boston U.S.A., 2000.

34. Grande, D.; Penelle, J.; Davidson, P.; Beurroies, I.; Denoyel, R., Functionalized ordered nanoporous polymeric materials: From the synthesis of diblock copolymers to their nanostructuration and their selective degradation. Microporous and Mesoporous Materials 2011, 140 (1), 34-39.

35. Binder, W. H.; Sachsenhofer, R., 'Click' Chemistry in Polymer and Materials Science. Macromolecular Rapid Communications 2007, 28 (1), 15-54.

36. Binder, W. H.; Sachsenhofer, R., 'Click' Chemistry in Polymer and Material Science: An Update. Macromolecular Rapid Communications 2008, 29 (12 - 13), 952-981.

37. Moses, J. E.; Moorhouse, A. D., The growing applications of click chemistry. Chemical Society Reviews 2007, 36 (8), 1249-1262. 
38. Choi, J.-H.; Gu, Y.; Hong, K.; Xie, W.; Frisbie, C. D.; Lodge, T. P., High Capacitance, Photo-Patternable Ion Gel Gate Insulators Compatible with Vapor Deposition of Metal Gate Electrodes. ACS Applied Materials \& Interfaces 2014, 6 (21), 19275-19281.

39. Doran, S.; Yagci, Y., Graft polymer growth using tandem photoinduced photoinitiator-free CuAAC/ATRP. Polymer Chemistry 2015, 6 (6), 946-952.

40. Gu, Y.; Zhang, S.; Martinetti, L.; Lee, K. H.; Mclntosh, L. D.; Frisbie, C. D.; Lodge, T. P., High Toughness, High Conductivity Ion Gels by Sequential Triblock Copolymer Self-Assembly and Chemical Cross-Linking. Journal of the American Chemical Society 2013, 135 (26), 9652-9655.

41. Li, Y.; Michinobu, T., Click synthesis and reversible electrochromic behaviors of novel polystyrenes bearing aromatic amine units. Journal of Polymer Science Part A: Polymer Chemistry 2012, 50 (11), 2111-2120. 42. Li, Y.; Tsuboi, K.; Michinobu, T., Double Click Synthesis and Second-Order Nonlinearities of Polystyrenes Bearing Donor-Acceptor Chromophores. Macromolecules 2010, 43 (12), 5277-5286.

43. Lorenz, M.; Paganini, C.; Storti, G.; Morbidelli, M., Macroporous Polymer-Protein Hybrid Materials for Antibody Purification by Combination of Reactive Gelation and Click-Chemistry. Materials 2019, 12 (10), 1580 .

44. O'Shea, J.-P.; Solovyeva, V.; Guo, X.; Zhao, J.; Hadjichristidis, N.; Rodionov, V. O., Sequence-controlled copolymers of 2,3,4,5-pentafluorostyrene: mechanistic insight and application to organocatalysis. Polymer Chemistry 2014, 5 (3), 698-701.

45. Song, S.; Ko, Y.-G.; Lee, H.; Wi, D.; Ree, B. J.; Li, Y.; Michinobu, T.; Ree, M., High-performance triazolecontaining brush polymers via azide-alkyne click chemistry: a new functional polymer platform for electrical memory devices. NPG Asia Materials 2015, 7 (12), e228-e228.

46. Sun, Y.; Chen, Z.; Puodziukynaite, E.; Jenkins, D. M.; Reynolds, J. R.; Schanze, K. S., Light Harvesting Arrays of Polypyridine Ruthenium(II) Chromophores Prepared by Reversible Addition-Fragmentation Chain Transfer Polymerization. Macromolecules 2012, 45 (6), 2632-2642.

47. Urbani, C. N.; Bell, C. A.; Lonsdale, D. E.; Whittaker, M. R.; Monteiro, M. J., Reactive Alkyne and Azide Solid Supports To Increase Purity of Novel Polymeric Stars and Dendrimers via the "Click" Reaction. Macromolecules 2007, 40 (19), 7056-7059.

48. Yao, F.; Yan, G.-C.; Xu, L.-Q.; Fu, G.-D.; Yin, L.-H.; Pu, Y.-P.; Kang, E.-T., Hairy fluorescent nanoparticles from one-pot click chemistry and atom transfer radical emulsion polymerization. Polymer International 2014, 63 (2), 237-243.

49. Kim, M.-J.; Yu, Y.-G.; Chae, C.-G.; Seo, H.-B.; Lee, J.-S., Facile Synthesis of Amphiphilic Bottlebrush Block Copolymers Bearing Pyridine Pendants via Click Reaction from Protected Alkyne Side Groups. Macromolecules 2020, 53 (6), 2209-2219.

50. Coessens, V.; Pintauer, T.; Matyjaszewski, K., Functional polymers by atom transfer radical polymerization. Progress in Polymer Science 2001, 26 (3), 337-377.

51. Lenstra, D. C.; Wolf, J. J.; Mecinović, J., Catalytic Staudinger Reduction at Room Temperature. The Journal of Organic Chemistry 2019, 84 (10), 6536-6545.

52. Kim, Y.; Rhee, Y. H.; Park, J., Redox reaction between benzyl azides and aryl azides: concerted synthesis of aryl nitriles and anilines. Organic \& Biomolecular Chemistry 2017, 15 (7), 1636-1641.

53. Damiron, D.; Okhay, N.; Akhrass, S. A.; Cassagnau, P.; Drockenmuller, E., Crosslinked PDMS elastomers and coatings from the thermal curing of vinyl-functionalized PDMS and a diazide aliphatic crosslinker. Journal of Polymer Science Part A: Polymer Chemistry 2012, 50 (1), 98-107. 